\title{
Special Issue on "Global Information Multimedia Communication Village (GIMCV)" (Selected Topics from the Strategic Workshop, May 28-30, 2008, Madeira, Portugal)
}

\author{
Marina Ruggieri • Ole Brun Madsen
}

Published online: 27 March 2009

(C) Springer Science+Business Media, LLC. 2009

The 10th edition of the closed-door Strategic Workshop has been held in Madeira, Portugal from 28th to 30th May 2008, focussing on the key-topic for the perspective of Global Information Multimedia Communication Village (GIMCV).

The GIMCV is a very significant concept for the growth of future wireless communication technologies. This concept has been very well explained in 12 selected papers published in this special issue.

The first paper, "The Top 10 List for Terabit Speed Wireless Personal Services", by Ramjee Prasad, Parag Pruthi and Kishore Ramareddy, discusses an overview of the top 10 areas, which in unison can provide a resilient infrastructure for widespread and rapid adoption of personal services.

The second paper, "Overall Requirements for Global Information Multimedia Communication Village", by Antonio Cimmino and Pascale Donadio, explains some of the complex objectives and main challenges that telecommunication solution and services have to deal with in order to respect both specific requirements of global user interactions, habits, and personalization and framework requirements about green environments.

The third paper, "Role of Convergence in GIMCV Development: A Vision", by Mari Carmen Aguayo-Torres, José Tomás Entrambasaguas Muñoz, Javie Poncela Gonzáles and Gerardo Gómez Paredes, presents vision on how convergence will lead the GIMCV development.

The fourth paper, "An Operational Conceptual Model for Global Communication Infrastructure", by Rui L. Aguiar, Hans Joachim Einsiedler and Jose Ignacio Moreno, discusses a novel model for structuring communication networks which closely reflects the visions and needs from an operational network.

\section{Ruggieri $(\varangle)$}

Department of Electronics Engineering, University Roma Tor Vergata,

Via Politecnico 1, 00133 Roma, Italy

e-mail: ruggieri@uniroma2.it

O. B. Madsen

Aalborg University, Inst. 8-Kommunikationsteknologi Niels Jernes Vej 12,

Room a5-213, 9220 Aalborg, Denmark 
The fifth paper "Identities in the Future Internet of Things", by Amardeo Sarma and João Girão addresses problems associated with the diversifying of the Internet towards an Internet of Things, and with increased ways to be reachable, whether the user wants it or not, in the digital world.

The sixth paper, "Fast Running Technologies and Their Impact on Fast Growing Industries", by Debasis Bandyopadhyay, tries to explore a few current R\&D work in identified technology domains namely multimedia, wireless communication and its security and some value adding applications that are under development on those areas.

The seventh paper, "Resource Allocation in Cognitive Radio Networks: a Comparison between Game Theory based and Heuristic Approaches", by Enrico Del Re, Gherardo Gorni, Luca Simone Ronga and Rosalba Suffritti shows the potential benefits of the adoption of a cognitive radio strategy to the coexistence problem. Two different approaches have been considered: the first one is based on the Game Theory while the second one is formalized as a constrained maximum search and represent the optimum solution.

The eighth paper titled "Municipalities as a Driver for Wireless Broadband Access", by Jan Van Ooteghem, Bart Lannoo, Koen Casier, Sofie Verbrugge, Emmeric Tanghe, Wout Joseph, Luc Martens, Didier Colle, Mario Pickavet, Ingrid Moerman and Piet Demeester evaluates a wireless municipality network from both a technical and an economic point of view. WiFi and WiMAX are considered as the most suited technologies for this purpose.

The ninth paper, "Co-opetition Enabling Security for Cooperative Networks-Authorising Composition Agreement Negotiations between Ambient Networks", by Peter Schoo, presents the approach and procedure for authorizing the negotiations between networks that want to compose to improve the network owner position regarding co-opetition.

The tenth paper titled, "User Driven Innovation-Involving Users of the Global Information Multimedia Communication Village in the Creation of a Devise for Personal Healthcare: maXi", by Christian Kloch, Niels Boye and Torben Jørgensen, investigates how personal chronic disease management can be supported by ICT, especially for people with diabetes type 1 .

The eleventh paper, "An Architectural Framework and Enabling Wireless Technologies for Digital Cities and Intelligent Urban Environments", by Gregory S. Yovanof and George $N$. Hazapis, analyses intelligent city services from the electronic information and communication perspective.

The last paper, "Collaborative Network Transformation", by Vish Ramamurti explores the task of network transformation and highlights the complexity involved.

\section{Author Biographies}

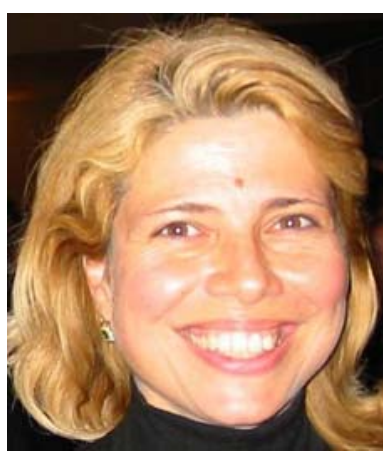

Marina Ruggieri graduated in Electronics Engineering at the University of Roma. She was: with FACE-ITT and GTC-ITT (Roanoke, VA) in the High Frequency Division (1985-1986); Research and Teaching Assistant at the University of Roma Tor Vergata (1986-1991); Associate Professor in Telecommunications at University of L'Aquila (19911994) and at Tor Vergata (1994-2000). Since November 2000 she is Full Professor in Telecommunications at Tor Vergata. Since 2003 she directs a Master in "Advanced Satellite Communications and Navigation Systems" at Tor Vergata. Her research focuses on space communications and navigation systems, integrated systems, mobile and multimedia networks. Since 1999 she is in the Board of Governors of the IEEE Aerospace and Electronic Systems (AES) Society and, since 2005, Director for AESS Operations in Italy \& Western Europe. Since January 2008 she is Executive Vice President of the IEEE AESS. She was in the Technical-Scientific Committee of the Italian Space Agency (ASI) 
in 2004-2006 and in 2007-2008 as Vice-President. Since December 2007 she belongs to the Italian Superior Council of Telecommunications as Expert. Since December 2006 she is Vice-President of the AFCEA Rome Chapter. In 2006-2007 she was Italian representative in Communications Systems Technical Committee of the International Federation for Information Processing. She is Director of CTIF_Italy, the Italian branch of the Center for Teleinfrastruktur (CTIF) in Aalborg (Danimarca), opened on September 28, 2006 at Tor Vergata. She is Editor of the IEEE Transactions on AES for "Space Systems", Chair of the IEEE AES Space Systems Panel, Assistant Editor of the IEEE Aerospace and Electronic Systems Magazine. She was awarded the 1990 Piero Fanti International Prize and she had a nomination for the Harry M. Mimmo Award in 1996 and the Cristoforo Colombo Award in 2002. She is author of about 250 papers, on international journals/transactions and proceedings of international conferences, book chapters and books. Among the most recent books:

- R. Prasad, M. Ruggieri, "Applied Satellite Navigation using GPS, GALILEO, and Augmentation Systems", Artech House, Boston, 2005 (ISBN: 1-58053-814-2).

- E. Del Re e M. Ruggieri (Eds), "Satellite Communications and Navigation Systems", Springer, 2008 (ISBN: 978-0-387-47522-6; e-ISBN: 978-0-387-47524-0).

- P. Finocchio, R. Prasad e M. Ruggieri (Eds), "Aerospace Technologies and Applications for Dual Use-A New World of Defense and Commercial in 21st Century Security", River Publishers, 2008 (ISBN: 978-8792329-04-2, e-ISBN: 978-87-92329-05-9).

She is IEEE (S'84-M'85-SM'94), AFCEA, IIN and AICA Member.

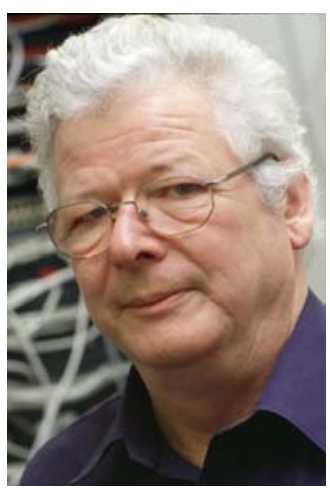

Ole Brun Madsen was born in 1942 in Denmark and received his M.Sc. in Mathematics and Computer Science from the University of Copenhagen. 1962-1972: Researcher and from 1968 head of the Computer Science Laboratory at The Royal Danish Academy of Fine Arts in Copenhagen. 1972-1981: Head of the Development Department, RECAU, the Regional Computing Centre at Århus University. 19811996: Head of the Data Network Section and Head of the Network Infrastructure Strategy section at Jutland Telephone. 1996-1999: Manager for Infrastructure Network Technology and Strategy at TDC, Tele Denmark. (1999-) Professor in Distributed real-time Systems and from 2004 as Head of CNP, Center for Network Planning and Co-director for CTIF, Center for TeleInFrastructur at Aalborg University. He has been project leader for a number of national and international $R \& D$ projects and acted in high level advisory tasks within the European Commission on the R\&D framework programmes in DGXIII and with United Nations UNDP activities. Present research is focused on Infrastructure Architecture and Modelling Tools for Network Analysis and Design. 